\title{
La investigación original y la Revista Mexicana de Oftalmología
}

\section{Original research and the Mexican Journal of Ophthalmology}

\author{
Roberto González-Salinas ${ }^{1}$ y Manuel A. Garza-León ${ }^{2 *}$ \\ ${ }^{1}$ Coeditor; ${ }^{2}$ Editor Jefe. Revista Mexicana de Oftalmología, Sociedad Mexicana de Oftalmología, Ciudad de México, México
}

«La ciencia de hoy se convertirá en la tecnología de mañana» Edward Teller

El pensamiento científico es indispensable para evaluar de manera crítica las deliberaciones alrededor de los nuevos conocimientos, así como para comprender y aprovechar al máximo las publicaciones de investigación, de manera que nos sea posible practicar la oftalmología sobre una base sólida.

En esta edición, en la Revista Mexicana de Oftalmología se publican cuatro estudios originales, uno de ellos trata sobre la innovación en investigación básica. El artículo, enviado por la Dra. Zavala, et al. ${ }^{1}$ y titulado «Expresión de genes del metabolismo de lípidos y colesterol en fibroblastos", es un ejemplo que nos sirve para reafirmar el impacto y alcance que tiene la investigación básica en la oftalmología para contribuir a la caracterización y profundización en el conocimiento de las enfermedades oculares.

A través de estudios de investigación como este, los esfuerzos de investigadores de ciencias tanto básicas como clínicas se han traducido en ensayos clínicos para prevenir, tratar y curar enfermedades oculares. La Revista Mexicana de Oftalmología, de esta forma, refrenda su irrenunciable compromiso con el apoyo a la investigación original de calidad, cuyas iniciativas se traduzcan en avances en la investigación de la visión, con un impacto directo y profundo en la atención al paciente, mediante un enfoque interdisciplinario de variados campos de la ciencia, la ingeniería biomédica y la medicina para hacer avances en la ciencia de la visión, así como en la oftalmología clínica.
Estamos entusiasmados de comenzar un nuevo año de la Revista Mexicana de Oftalmología con artículos de ciencias básicas y clínicas de alta calidad. Los artículos seleccionados en este número fueron revisados y escogidos a partir de los estudios originales enviados para ser considerados para su publicación en la revista, provenientes de múltiples instituciones de nuestro país, América Latina y Europa, lo cual nos enorgullece y compromete a promover el fortalecimiento y difusión de trabajos científicos en oftalmología.

Como mencionamos en el editorial inicial de 2018², la Revista Mexicana de Oftalmología solicitó su inclusión en la indización PubMed/MEDLINE. A este respecto, aunque mejoramos nuestra puntuación en métricas clave en comparación con la aplicación anterior en el 2015 (3.5 vs. 3.0 puntos), no fue suficiente para ser incluidos en esta base de datos. Se señaló como una de las áreas a mejorar la cantidad y calidad de estudios de investigación original, así como de revisiones sistemáticas o metaanálisis. Por ello, queremos aprovechar este espacio para invitarles a seguir contribuyendo en el avance de la Revista Mexicana de Oftalmología a través de estudios originales de alta calidad.

En los últimos dos años, la Revista Mexicana de Oftalmología ha incrementado el número de artículos recibidos para su consideración; de los 195 artículos recibidos durante este período, con apoyo de los revisores y el comité editorial hemos mantenido una tasa de aceptación similar a las mejores revistas de oftalmología del mundo, con el objetivo de entregar a 
nuestros lectores información de alta calidad científica que a su vez refleje la oftalmología no solo de México sino de toda Hispanoamérica.

Esperamos seguir contando con su confianza y trabajaremos para mantener y mejorar la calidad científica de nuestra revista.

\section{Bibligografía}

1. Zavala J, Treviño V, Reyna-Fuentes AA, Arellano-Gurrola CM, Enriquez-Ochoa D, et al. Expresión de genes del metabolismo de lípidos y colesterol en fibroblastos de pterigión: análisis comparativo con adipocitos y otros fibroblastos. Rev Mex Oftalmol. 2019;93(1):7-13.

2. Garza-León M, González-Salinas R, Guerrero-Berger O, García-Aguirre G. Un nuevo cambio, nuevas oportunidades. Rev Mex Oftalmol. 2018;92(1):5 